Archive for

Organic Chemistry

Arkivoc 2017, part i, 67-83

\title{
Application of fluoroform in trifluoromethylation and difluoromethylation reactions
}

\author{
Cai Zhang
}

Department of Architecture and Environment, Chongqing Vocational Institute of Safety Technology, Chongqing 404 020, People's Republic of China

E-mail: stezh64@163.com

Received 09-18-2016

Accepted 12-10-2016

Published on line 03-12-2017

\section{Abstract}

Recent development in the trifluoromethylation and difluoromethylation of organic compounds employing fluoroform is reviewed. Eight approaches to trifluoromethylation and difluoromethylation are summarized: (i) trifluoromethylation or difluoromethylation of carbonyl compounds, (ii) trifluoromethylation of sulfonyl fluorides, (iii) trifluoromethylation of epoxides, (iv) nucleophilic trifluoromethylation of silicon, boron, and sulfur-based compounds, (v) $\mathrm{CuCF}_{3}$ derived from fluoroform for the trifluoromethylation of aryl or heteroaryl halides, aryl boronic acids, arenediazonium salts and alkynes, (vi) difluoromethylation of alkynes, (vii) difluoromethylation of phenols, thiophenols and heterocyclic compounds, and (viii) difluoromethylation of nitriles.

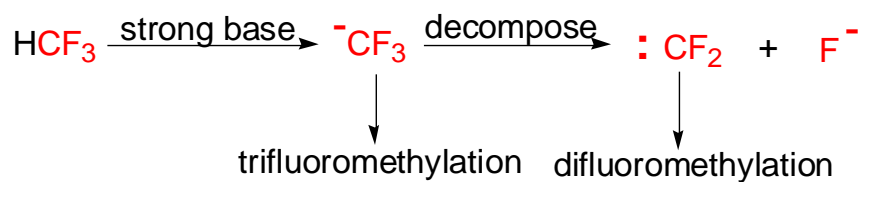

Keywords: Trifluoromethylation, difluoromethylation, fluoroform, $\mathrm{CuCF}_{3}$ 


\section{Table of Contents}

1. Introduction

2. Application of Fluoroform in Trifluoromethylation and Difluoromethylation

2.1 Trifluoromethylation or difluoromethylation of carbonyl compounds

2.2 Trifluoromethylation of sulfonyl fluorides

2.3 Trifluoromethylation of epoxides

2.4 Nucleophilic trifluoromethylation of silicon, boron, and sulfur-based compounds

2.5 $\mathrm{CuCF}_{3}$ derived from fluoroform for the trifluoromethylation of aryl or heteroaryl halides, aryl boronic acids, arenediazonium salts and alkynes

2.6 Difluoromethylation of alkynes

2.7 Difluoromethylation of phenols, thiophenols and heterocyclic compounds

2.8 Difluoromethylation of nitriles

3. Conclusions

4. Acknowledgements

5. References

\section{Introduction}

In recent years, the organic fluorine compounds, such as trifluoromethylated and difluoromethylated molecules, have been widely concerned in pharmaceutical and agrochemical research, ${ }^{1-3}$ because the trifluoromethyl and difluoromethyl groups can improve the binding selectivity, lipophilicity and metabolic stability of these compounds. ${ }^{4}$ Recently, a series of fluorine reagents, such as Umemoto's reagents, ${ }^{5-10}$ $\mathrm{NaSO}_{2} \mathrm{CF}_{3}{ }^{11-15} \mathrm{CF}_{3} \mathrm{SiMe}_{3},{ }^{16}$ Togni's reagents, ${ }^{17-19}$ and $\mathrm{TMSCF}_{2} \mathrm{H}_{1}{ }^{20,21}$ were employed in the transformations of these fluorine functional groups. However, reports on the application of fluoroform (a cheap, nontoxic and not an ozone-depleting gas $^{22}$ ) in trifluoromethylation and difluoromethylation reactions are rare. ${ }^{23}$ This review provides an overview of trifluoromethylation and difluoromethylation using fluoroform over the period from 2010 to the present. Several approaches will be reviewed and divided into (i) trifluoromethylation or difluoromethylation of carbonyl compounds, (ii) trifluoromethylation of sulfonyl fluorides, (iii) trifluoromethylation of epoxides, (iv) nucleophilic trifluoromethylation of silicon, boron, and sulfur-based compounds, (v) $\mathrm{CuCF}_{3}$ derived from fluoroform for the trifluoromethylation of aryl or heteroaryl halides, aryl boronic acids, arenediazonium salts and alkynes, (vi) difluoromethylation of alkynes, (vii) difluoromethylation of phenols, thiophenols and heterocyclic compounds, and (viii) difluoromethylation of nitriles.

On the basis of a large amount of research literature, ${ }^{24-26}$ a proposed mechanism for trifluoromethylation and difluoromethylation reactions employing fluoroform is depicted in Scheme 1 . Due to the weak acidity of $\mathrm{HCF}_{3},{ }^{27}$ in the presence of the strong bases, such as $t-\mathrm{BuOK},\left[\left(\mathrm{Me}_{2} \mathrm{~N}\right)_{3} \mathrm{PN}\right]_{3} \mathrm{PNCMe}_{3}, \mathrm{MeSOCH}_{2} \mathrm{~K}, n$-BuLi and so on, fluoroform can produce the trifluoromethyl anion $\left(\mathrm{CF}_{3}{ }^{-}\right)$, which is a very important intermediate in trifluoromethylation reactions. ${ }^{16}$ The trifluoromethyl anion, as an unstable intermediate, can undergo decomposition to generate fluoride anion $\left(\mathrm{F}^{-}\right)$and difluorocarbene, ${ }^{28}$ which can then react with substrates to afford difluoromethylated products. ${ }^{29,30}$ 


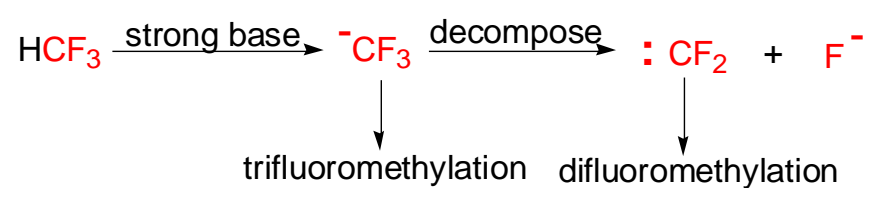

Scheme 1. A proposed mechanism for trifluoromethylation and difluoromethylation reactions employing fluoroform.

\section{Application of Fluoroform in Trifluoromethylation and Difluoromethylation}

\subsection{Trifluoromethylation or difluoromethylation of carbonyl compounds}

As early as 1998-2000, an effective nucleophilic trifluoromethylation of carbonyl compounds employing fluoroform as a $\mathrm{CF}_{3}$ source in the presence of a common base [t-BuOK, $\mathrm{MeSOCH}_{2} \mathrm{~K}$, electrogenerated or silicon-containing base] was developed by the research groups of Roques, Normant, Troupel and Langlois. ${ }^{26,31-}$ ${ }^{34}$ A series of aldehydes and ketones were tested for trifluoromethylation, and gave moderate to good yields of the target products $\mathbf{2}$ in most cases.

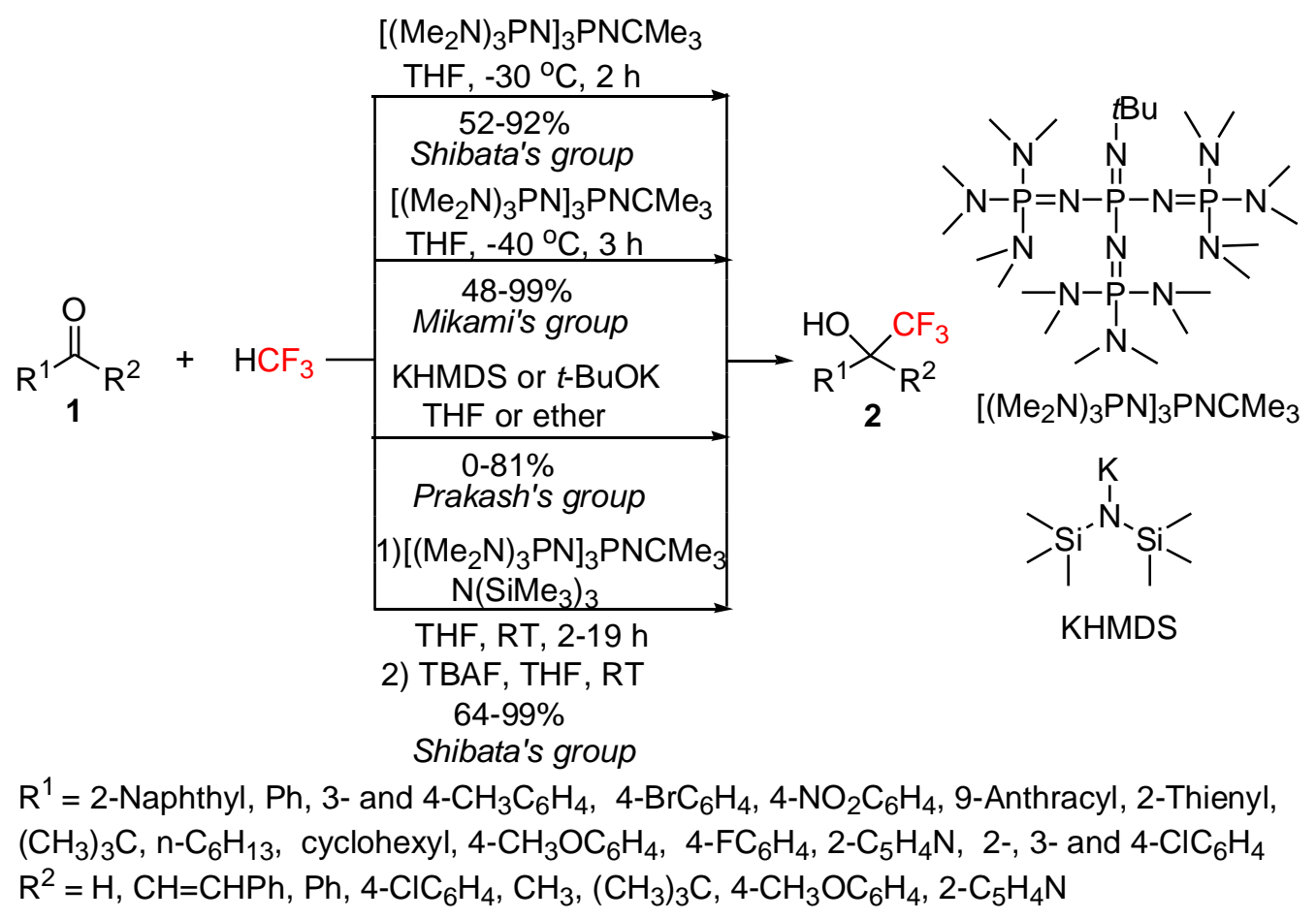

Scheme 2. Trifluoromethylation of aldehydes and ketones.

In 2012, 2013 and 2015, some new type bases, such as $\left[\left(\mathrm{Me}_{2} \mathrm{~N}\right)_{3} \mathrm{PN}\right]_{3} \mathrm{PNCMe}_{3}$ and KHMDS, applied in the nucleophilic trifluoromethylation of aldehydes, ketones, carboxylic acid esters or halides were developed by the research groups of Prakash, Shibata and Mikami (Schemes 2 and 3). ${ }^{24,35-37}$ In these studies, various carbonyl compounds were scrutinized, giving moderate to good yields of products 2, $\mathbf{4}$ or $\mathbf{5}$ in most cases. Prakash et al. showed that all the trifluoromethylation reactions, performed in THF or ether instead of DMF as solvent in the presence of fluoroform as a $\mathrm{CF}_{3}$ source and KHMDS or $t$-BuOK as a base, afforded the desired 
products 2 in $0-81 \%$ yields (Scheme 2). ${ }^{35}$ When the chalcone containing a nitro group in the para position of the benzoyl group was employed for this transformation, however the target product 2 was not obtained. ${ }^{35}$ The other two research groups, such as Shibata and Mikami, both reported that in the effect of $\left[\left(\mathrm{Me}_{2} \mathrm{~N}\right)_{3} \mathrm{PN}\right]_{3} \mathrm{PNCMe}_{3}$ as base, fluoroform was used for difluoromethylation reaction at lower temperature ($30{ }^{\circ} \mathrm{C}$ or $-40{ }^{\circ} \mathrm{C}$ ) or room temperature, and produced the compounds $\mathbf{2}$ in moderate to excellent yields (Shibata: 52-92\% and 64-99\%, Mikami: 48-99\%, respectively). ${ }^{24,36,37}$

In addition, the carboxylic acid esters and halides 3 were also employed for trifluoromethylation by Mikami and co-workers (Scheme 3). ${ }^{36}$ It is very interesting that when benzoyl chloride and 1.2 equiv $\left[\left(\mathrm{Me}_{2} \mathrm{~N}\right)_{3} \mathrm{PN}\right]_{3} \mathrm{PNCMe}_{3}$ were used for this transformation, the reaction time had no effect on the yield of the product 4 ( $72 \%$ yield). However, in the presence of 2.4 equiv. [( $\left.\left.\mathrm{Me}_{2} \mathrm{~N}\right)_{3} \mathrm{PN}\right]_{3} \mathrm{PNCMe}$, as the reaction time was prolonged, the yield of the product $\mathbf{4}$ decreased gradually, while the yield of the product $\mathbf{5}$ gradually increased.

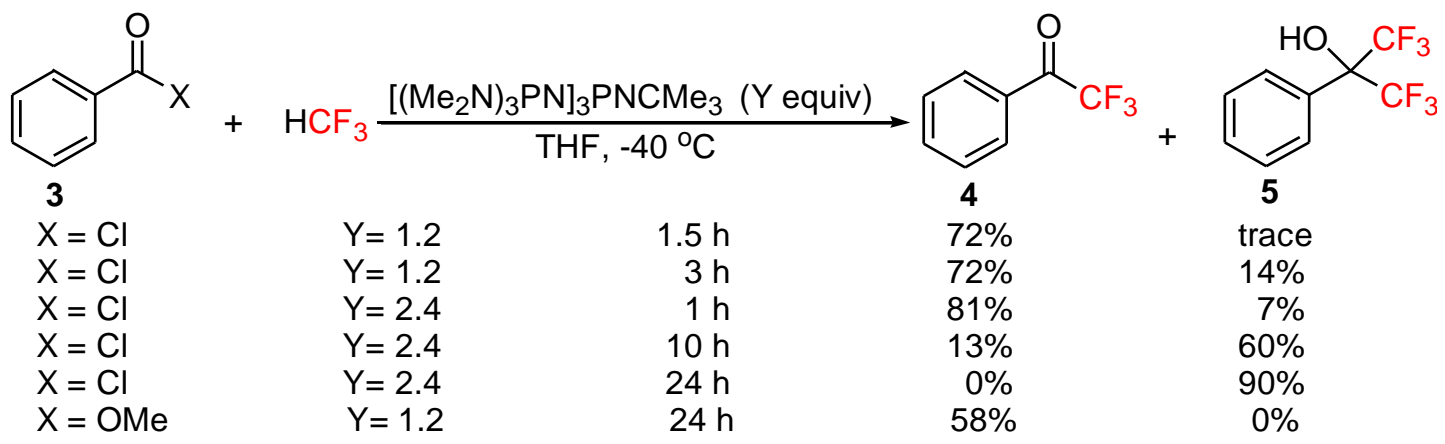

Scheme 3. Trifluoromethylation of the carboxylic acid esters and halides.

A proposed catalytic cycle for the trifluoromethylation using fluoroform as a $\mathrm{CF}_{3}$ source in the presence of $\left[\left(\mathrm{Me}_{2} \mathrm{~N}\right)_{3} \mathrm{PN}\right]_{3} \mathrm{PNCMe}_{3}$ and $\mathrm{N}\left(\mathrm{SiMe}_{3}\right)_{3}$, was described by Shibata and co-workers, ${ }^{37}$ as shown in Scheme 4 . The stabilized ion pair $\mathbf{A}$, arising from the reaction between substrate $\mathbf{1}$ and fluoroform in the presence of $\left[\left(\mathrm{Me}_{2} \mathrm{~N}\right)_{3} \mathrm{PN}\right]_{3} \mathrm{PNCMe}_{3}$, reacted with $\mathrm{N}\left(\mathrm{SiMe}_{3}\right)_{3}$ to produce the ion pair $\mathbf{C}$ and intermediate $\mathbf{B}$, which underwent a process of removing TMS to afford the desired product $\mathbf{2}$ in the effect of TBAF. The fluoroform, as a weak acid, would suffer a deprotonation reaction in the presence of the ion pair $\mathbf{C}$ to produce the trifluoromethyl anion $\left(\mathrm{CF}_{3}{ }^{-}\right)$, which can react with compound 1 and $\mathrm{H}\left[\left[\left(\mathrm{Me}_{2} \mathrm{~N}\right)_{3} \mathrm{PN}\right]_{3} \mathrm{PNCMe}\right]^{+}$also to give the stabilized ion pair A. In the entire reaction, $\mathrm{H}\left[\left[\left(\mathrm{Me}_{2} \mathrm{~N}\right)_{3} \mathrm{PN}\right]_{3} \mathrm{PNCMe}_{3}\right]^{+}$should play an important role in the trifluoromethylation. ${ }^{37}$ 


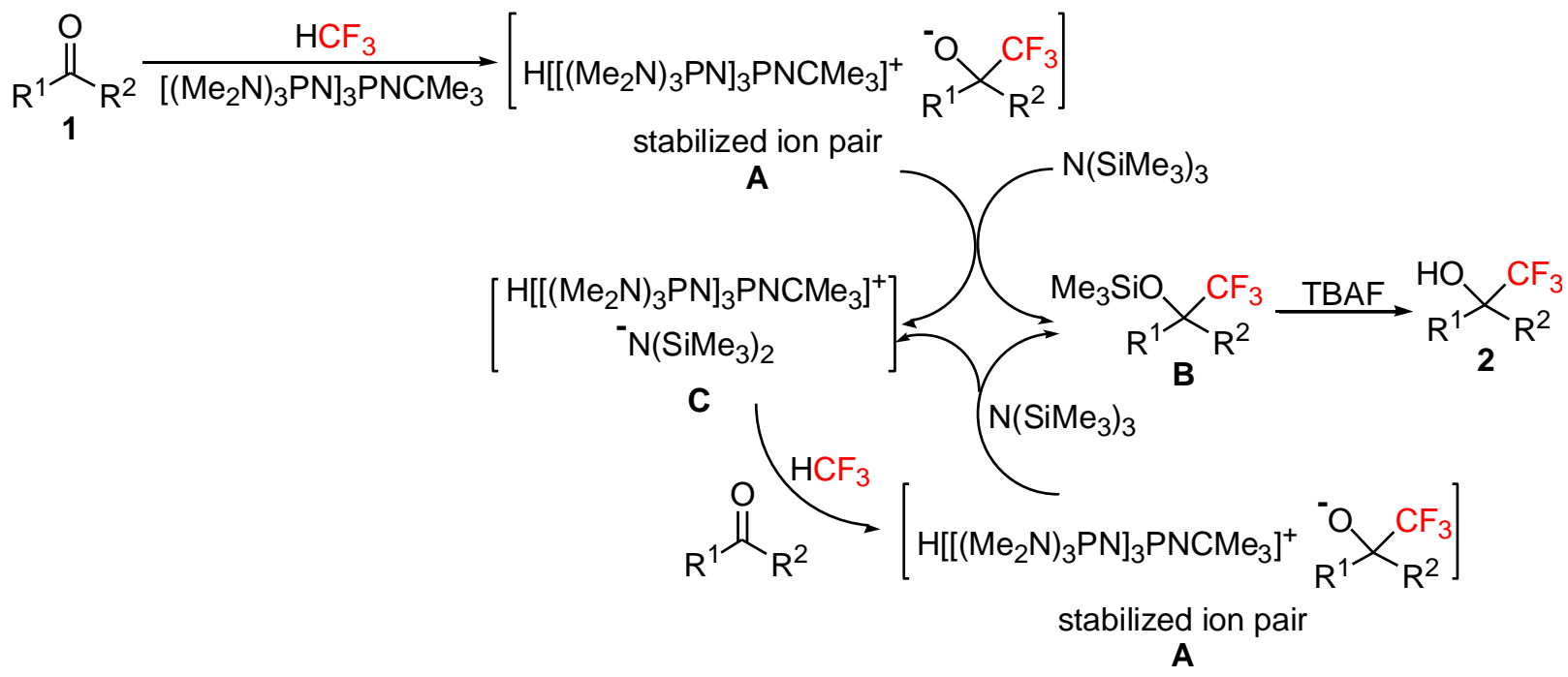

Scheme 4. A proposed catalytic cycle for the trifluoromethylation using fluoroform.

In 2013, Vugts and co-workers reported an efficient method for the synthesis of [ ${ }^{18} \mathrm{~F}$ ] trifluoromethylcontaining compounds $\mathbf{7}$ via a trifluoromethylation process using $\left[{ }^{18} \mathrm{~F}\right]$ fluoroform in the presence of $t$-BuOK as a base (Scheme 5). ${ }^{38}$ A series of aldehydes and ketones were found to undergo the desired transformations to give moderate to excellent yields of the corresponding products 7 in most cases. However, when the substrates 6 bearing an electron-withdrawing group such as 4-NO 2 and 3- $\mathrm{NO}_{2}$ in the aromatic ring, only trace amounts of the desired products 7 were afforded under the action of a smaller amount of $t$-BuOK.

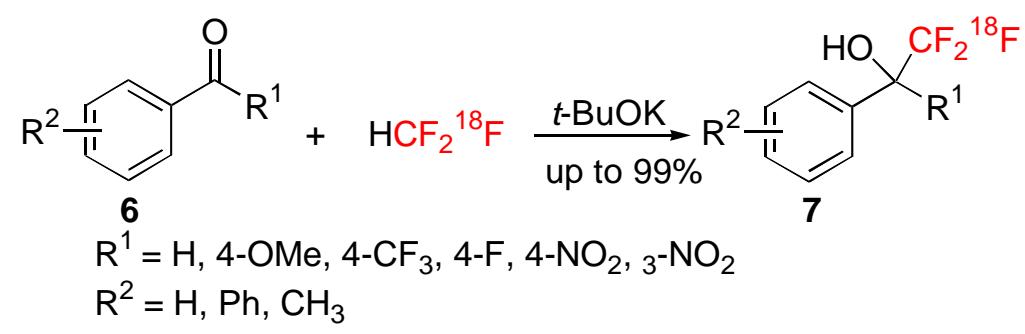

Scheme 5. An efficient method for the synthesis of $\left[{ }^{18} \mathrm{~F}\right]$ trifluoromethyl containing compounds.

In 2012, a direct $\alpha$-difluoromethylation of ketones for the synthesis of $\alpha$-difluoromethyl products 9 using fluoroform as a difluoromethylating reagent in the presence of LHMDS was developed by Mikami and coworkers (Scheme 6). ${ }^{39}$ Not only protected lactams $\mathbf{8 a}, \mathbf{b}, \mathbf{d}$-f but also the lactones $\mathbf{8 g}-\mathbf{i}$, ketone $\mathbf{8 j}$ and acyclic substrates $\mathbf{8 k - m}$ were all examined for $\alpha$-difluoromethylation, and afforded the $\alpha$-difluoromethyl products 9 in moderate to excellent yields (9a-b: 45-69\%, 9d-f: 37-64\%, 9g-i: 33-47\%, 9j: 36\%, 9k-m: 35-82\%). However, the $\alpha$-difluoromethylation of the $\alpha$-unsubstituted lactam $8 \mathrm{c}$ did not proceed well with $99 \%$ of the raw material $8 \mathrm{c}$ being recovered. 


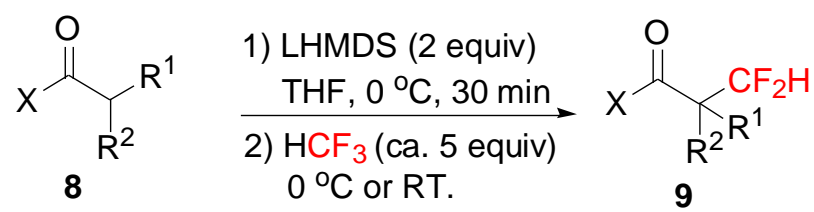

up to $82 \%$ yield

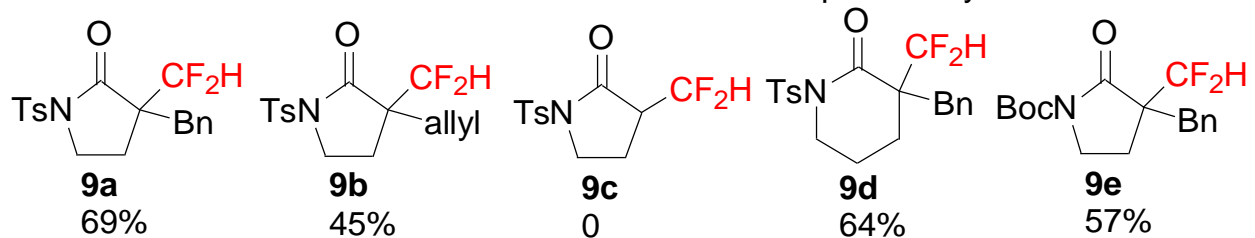

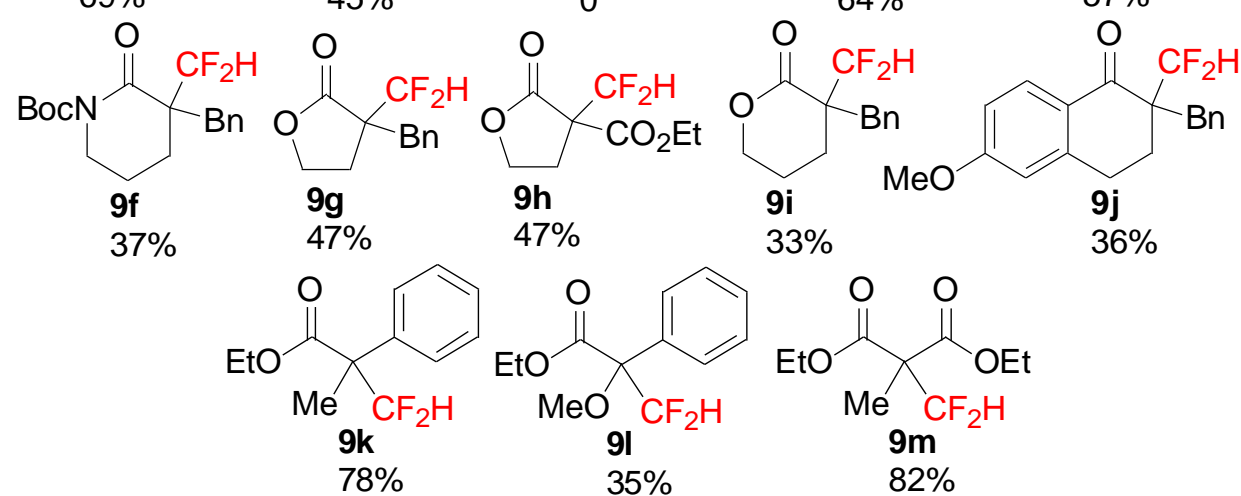

Scheme 6. A direct $\alpha$-difluoromethylation of ketones using fluoroform.

\subsection{Trifluoromethylation of sulfonyl fluorides}

In 2015, Shibata and co-workers developed an effective trifluoromethylation of sulfonyl fluorides 10 employing $\mathrm{N}\left(\mathrm{SiMe}_{3}\right)_{3}$ and excess $\mathrm{HCF}_{3}$, in the presence of a catalytic amount of $\left[\left(\mathrm{Me}_{2} \mathrm{~N}\right)_{3} \mathrm{PN}\right]_{3} \mathrm{PNCMe}_{3}$ (Scheme 7). ${ }^{37} \mathrm{~A}$ series of sulfonyl fluorides $\mathbf{1 0 a - g}$ bearing an electron-withdrawing or electron-donating group located on the aromatic ring, underwent the desired transformations, and afforded the aryl triflones $\mathbf{1 1}$ in good to high yields (11a-g: 50-84\%). Beyond that, the naphthyl-substituted sulfonyl fluorides $10 \mathrm{~h}, \mathrm{i}$ were also employed for the synthesis of aryl triflones, and give $60-78 \%$ yields of the the desired products $\mathbf{1 1 h}$, $\mathbf{i}$.

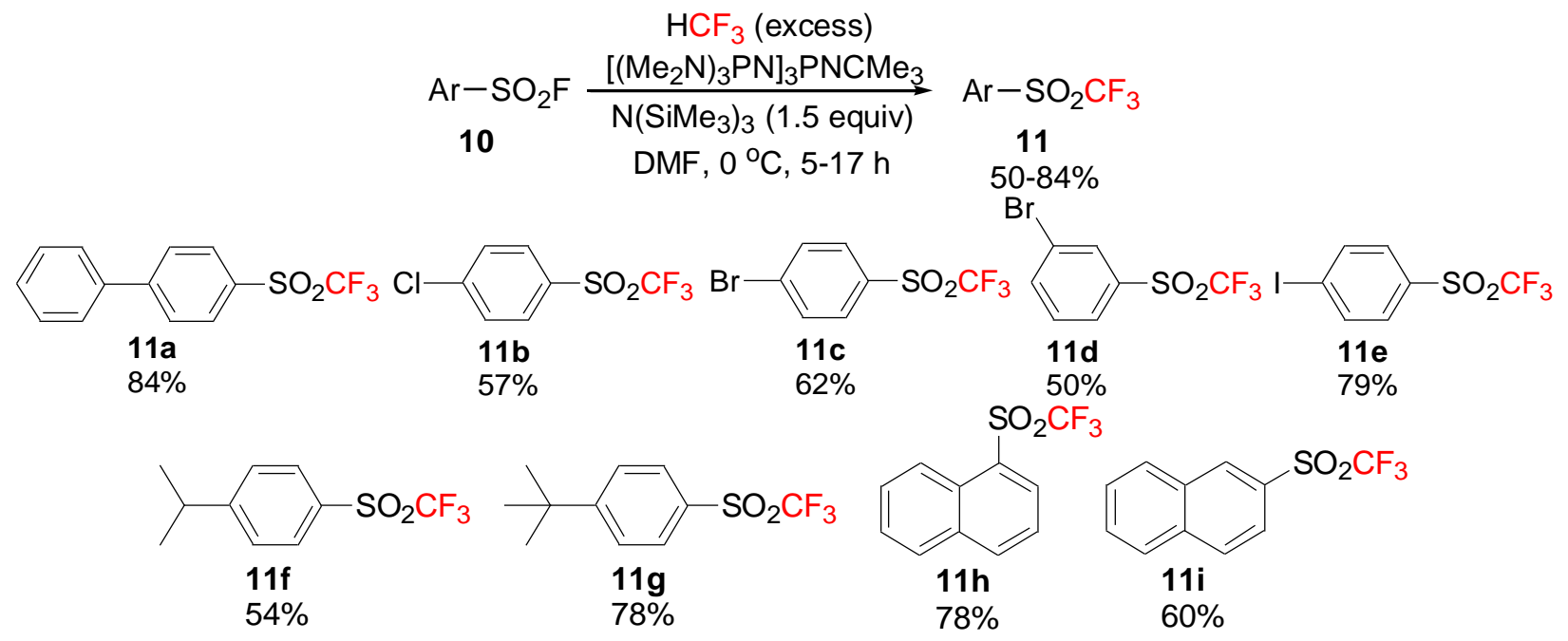


Scheme 7. Trifluoromethylation of sulfonyl fluorides.

\subsection{Trifluoromethylation of epoxides}

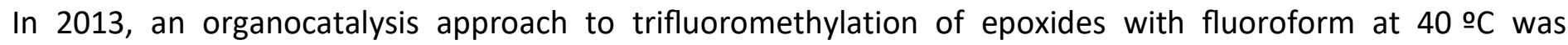
developed by Mikami and co-workers (Scheme 8). ${ }^{36}$ The epoxides 12 or 14 containing not only electronwithdrawing but also electron-donating groups, afforded the internal or terminal trifluoromethylation products 13 or 15 in 37-69\% yields. A suggested reaction mechanism, shown in Scheme 9, for the trifluoromethylation of epoxides was proposed by Mikami and co-workers. ${ }^{36}$ First of all, the $\left[\left(\mathrm{Me}_{2} \mathrm{~N}\right)_{3} \mathrm{PN}\right]_{3} \mathrm{PNCMe}_{3}$ reacts with epoxides 12 at the terminal carbon to afford the intermediates $\mathbf{A}$, which would undergo a hydrogen transfer process to produce methyl ketones $\mathbf{B}$. Then the ketones $\mathbf{B}$ are attacked by trifluoromethyl anion $\left(\mathrm{CF}_{3}{ }^{-}\right)$, arising from the reaction between fluoroform and $\left[\left(\mathrm{Me}_{2} \mathrm{~N}\right)_{3} \mathrm{PN}\right]_{3} \mathrm{PNCMe}$, to give the intermediates $\mathbf{C}$, which finally form the observed products $\mathbf{1 3}$, by proton transfer from $\mathrm{H}\left[\left[\left(\mathrm{Me}_{2} \mathrm{~N}\right)_{3} \mathrm{PN}\right]_{3} \mathrm{PNCMe}_{3}\right]^{+}$.<smiles>[X]c1ccc(C2CO2)cc1</smiles>

12 $37-69 \%$

13

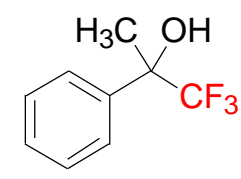

$13 a$

$51 \%$

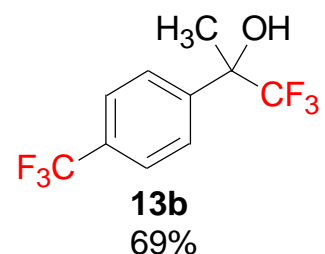

$69 \%$
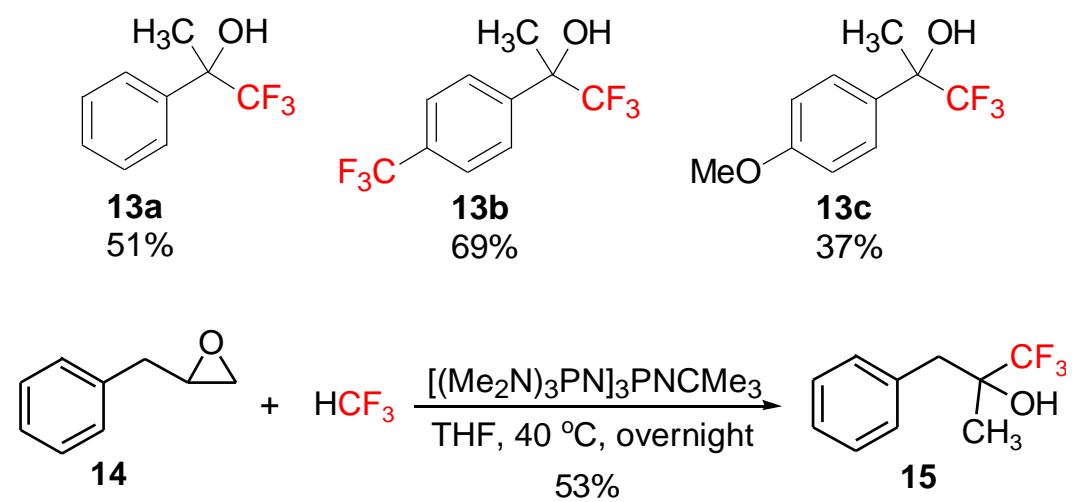

Scheme 8. Trifluoromethylation of of epoxides.

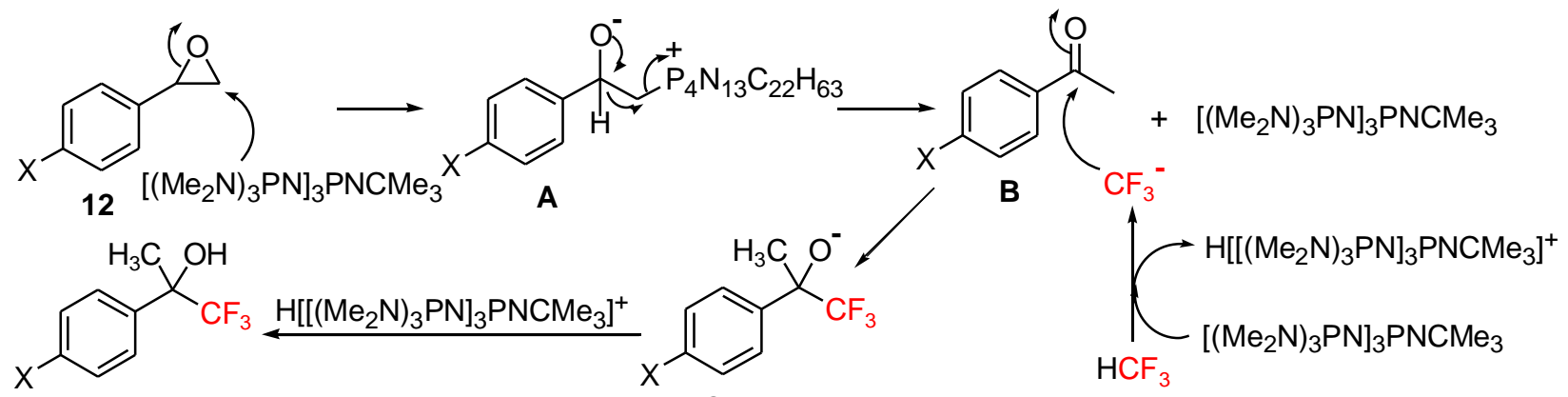
13

C

Scheme 9. A suggested reaction mechanism for the trifluoromethylation of epoxides. 


\subsection{Nucleophilic trifluoromethylation of silicon, boron, and sulfur-based compounds}

In 2012, Prakash and co-workers also reported a nucleophilic trifluoromethylation of silicon, boron, and sulfurbased compounds with $\mathrm{HCF}_{3}$ in the presence of KHMDS as base (Scheme 10). ${ }^{35}$ It was found that when $\mathrm{CF}_{3} \mathrm{H}$ was used for trifluoromethylation of silicon-based substrates 16, the desired products 17 were obtained in 42 $80 \%$ yields. In the effect of KHMDS, the boron-based compounds 18 can react with fluoroform, then followed by $48 \%$ aqueous $\mathrm{HF}$ to afford $\mathrm{CF}_{3} \mathrm{BF}_{3} \mathrm{~K} 19$ in $53 \%$ or $66 \%$ yield. The trifluoromethanesulfonic acid $\left(\mathrm{CF}_{3} \mathrm{SO}_{3} \mathrm{H}\right) \mathbf{2 0}$, a widely used and widely available organic acid, can be obtained in modest $18 \%$ conversion, in the presence of $\mathrm{CF}_{3} \mathrm{H}, \mathrm{S}_{8}, \mathrm{KHMDS}, 30 \% \mathrm{H}_{2} \mathrm{O}_{2}$ and $\mathrm{H}_{2} \mathrm{SO}_{4} \cdot{ }^{35}$ Because of low conversion rate of this synthesis procedure, we think that this preparation method of trifluoromethanesulfonic acid is not going to be economically viable.

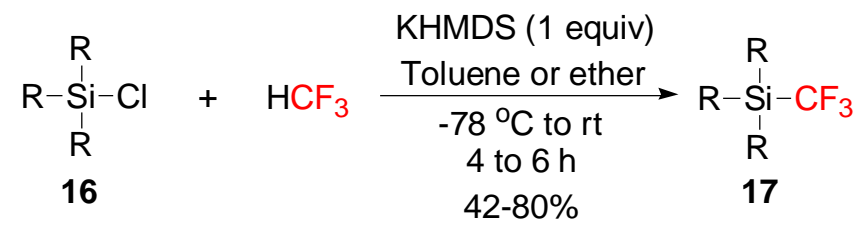

$$
\begin{aligned}
& \text { 1) KHMDS, THF }
\end{aligned}
$$

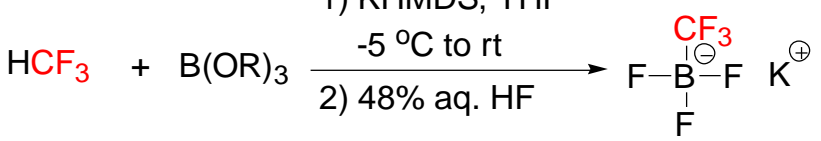

$$
\begin{aligned}
& \mathrm{R}=\mathrm{Me}, n-\mathrm{Bu} \\
& 18 \quad 53-66 \% \quad 19
\end{aligned}
$$

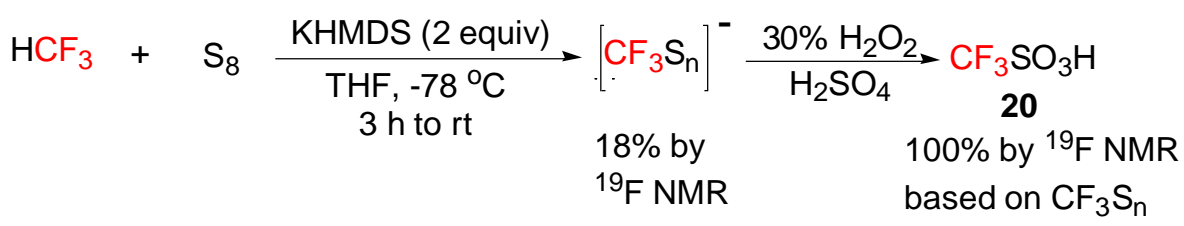

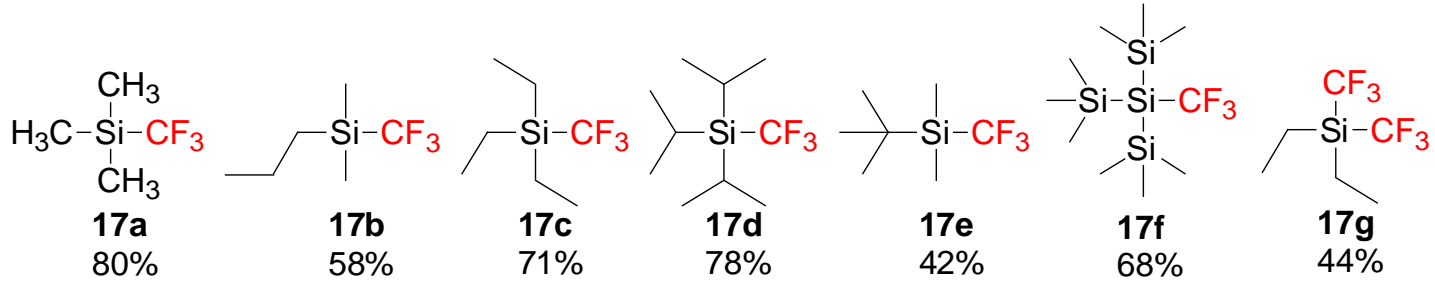

Scheme 10. Nucleophilic trifluoromethylation of silicon, boron, and sulfur-based compounds.

\section{5. $\mathrm{CuCF}_{3}$ derived from fluoroform for the trifluoromethylation of aryl or heteroaryl halides, aryl boronic acids, arenediazonium salts and alkynes}

In 2011, 2013, 2014 and 2016, $\mathrm{CuCF}_{3}$ derived from fluoroform for the trifluoromethylation of aryl boronic acids, arenediazonium salts, alkynes, aryl and heteroaryl halides was developed by the research groups of Grushin, Daugulis and Tsui (Scheme 11). ${ }^{40-45}$ All these research groups showed that $\mathrm{HCF}_{3}$ can react with $\mathrm{CuCl}$ in the presence of t-BuOK and DMF, or zinc bis-2,2,6,6-tetramethylpiperidide (TMP) $2 \mathrm{Zn}$, 1,3dimethylpropyleneurea (DMPU) and phenanthroline to produce fluoroform-derived $\mathrm{CuCF}_{3}$, which was a good 
trifluoromethylating reagent for the trifluoromethylation, $5,46,47$ and afforded the desired products $\mathbf{2 5 - 2 7}$ in moderate to excellent yields. ${ }^{40-45}$

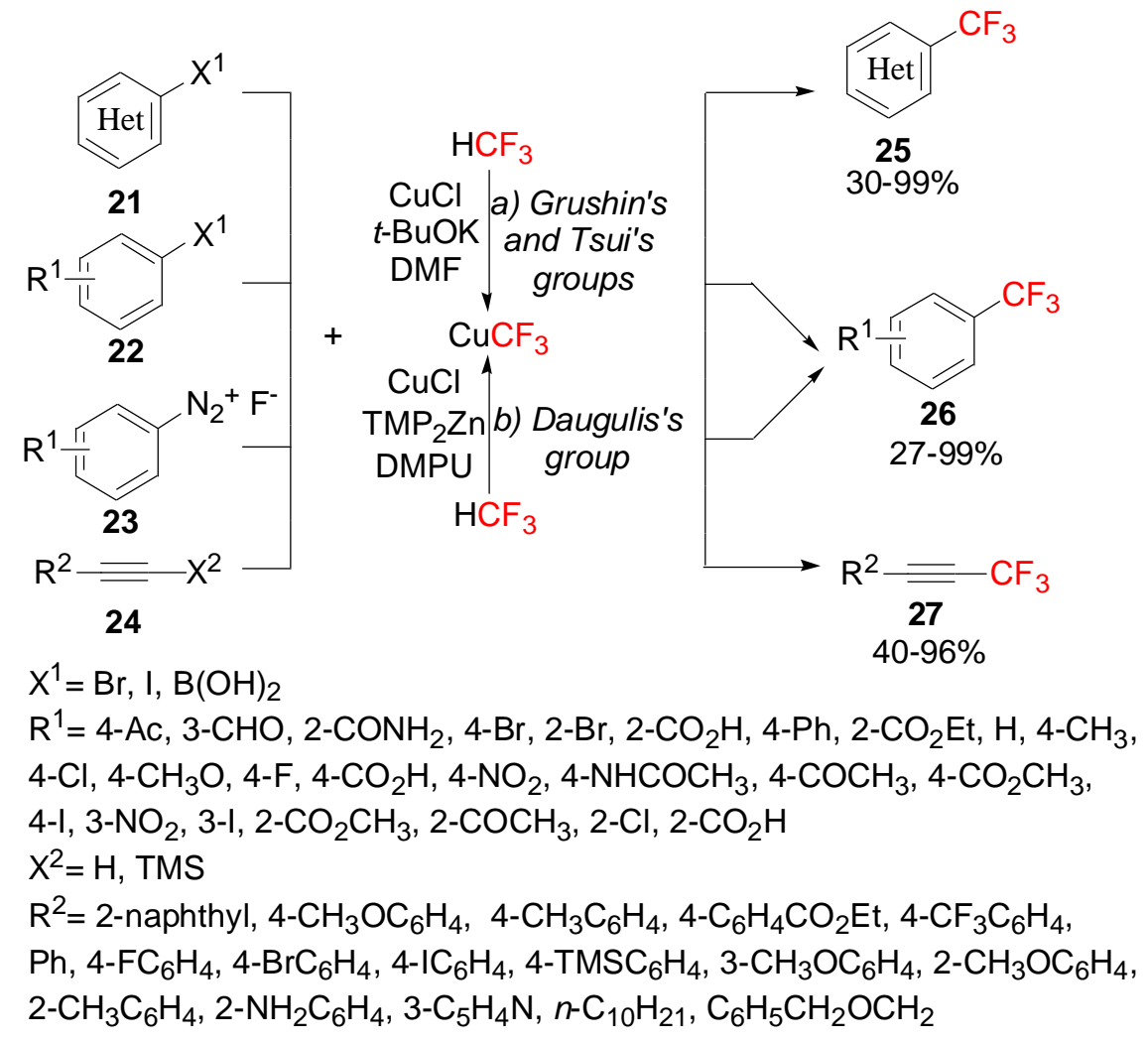

Scheme 11. Trifluoromethylation of aryl or heteroaryl halides, aryl boronic acids, arenediazonium salts and alkynes.

In 2014, a valuable method for the $\left[{ }^{18} \mathrm{~F}\right]$ trifluoromethylation of aryl iodides and aryl boronic acids in situ by use of $\mathrm{HCF}_{2}{ }^{18} \mathrm{~F}$ as the precursor of $\mathrm{CuCF}_{2}{ }^{18} \mathrm{~F}$ was described by Vugts and co-workers (Scheme 12). ${ }^{48}$ Under the optimized reaction conditions, a broad range of aryl iodides and aryl boronic acids can be converted successfully into the desired products $\mathbf{2 8}$ in moderate to excellent yields in many cases. From the experimental results, it can be seen that electronic effects seem to have no influence on the yields. However, the unprotected alcohol, carboxylic acid and amine did not perform well for the $\left.{ }^{18} \mathrm{~F}\right]$ trifluoromethylation reaction, and gave poor yields of the products $\mathbf{2 8 k}-\mathbf{m}$. When the substrates $\mathbf{2 8 n}, \mathbf{2 8 p}, \mathbf{2 8 q}$ and $\mathbf{2 9 h}$ were employed for the $\left[{ }^{18} \mathrm{~F}\right]$ trifluoromethylation, only $2-41 \%$ yields of the $\left[{ }^{18} \mathrm{~F}\right]$ trifluoromethyl arenes $30 \mathrm{n}, 30 \mathrm{p}, 30 \mathrm{q}$ and $\mathbf{3 0 h}$ were obtained. 


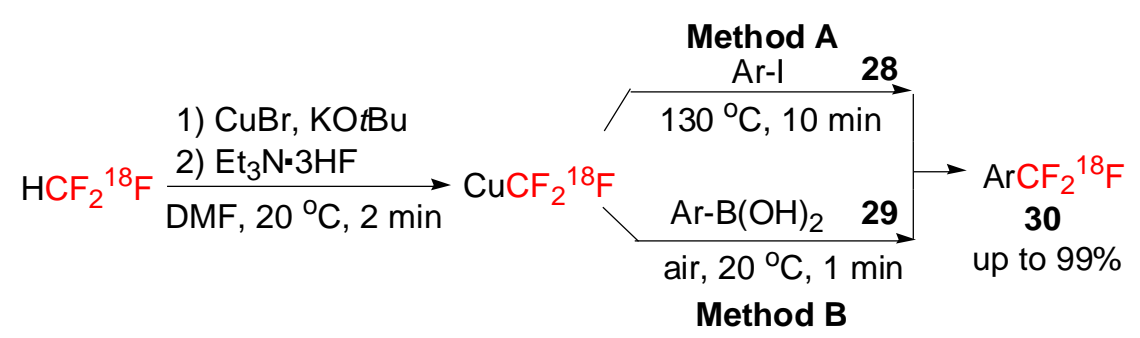

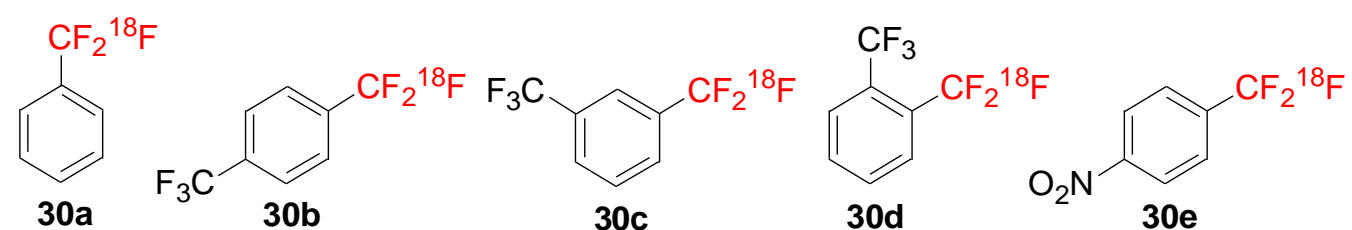
A: $61 \% \pm 2 \%$
A: $79 \% \pm 7 \%$
A: $82 \% \pm 5 \%$
A: $79 \% \pm 5 \%$
A: $86 \% \pm 4 \%$
B: $94 \% \pm 1 \%$
B: $84 \% \pm 8 \%$
B: $95 \% \pm 2 \%$
B: $96 \% \pm 3 \%$
B: $91 \% \pm 5 \%$<smiles>COc1ccc(C(F)(F)C(F)(F)C(F)(F)C(F)(F)c2ccc(C(F)(F)F)cc2)cc1</smiles>
A: $54 \% \pm 3 \%$
B: $94 \% \pm 2 \%$

A: $70 \% \pm 5 \%$
B: $95 \% \pm 1 \%$

A: $73 \% \pm 6 \%$

B: $4 \% \pm 2 \%$<smiles>O=Cc1ccc(C(F)(F)F)cc1</smiles><smiles>CC(=O)c1ccc([Ge]C(F)(F)F)cc1</smiles><smiles>Oc1ccc(C(F)(F)F)cc1</smiles>

A: $13 \% \pm 4 \%$ $\mathrm{HO}_{2}$

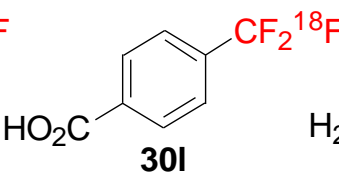

A: $3 \% \pm 1 \%$

B: $0 \% \pm 0 \%$
A: $89 \% \pm 2 \%$
B: $87 \% \pm 4 \%$

A: $61 \% \pm 2 \%$

B: $92 \% \pm 5 \%$<smiles>Nc1ccc(C(F)(F)F)cc1</smiles>

A: $48 \% \pm 4 \%$<smiles>CC(=O)Oc1ccc(C(F)(F)F)cc1</smiles><smiles>CC(=O)c1ccc(C(F)(F)F)cc1[O+]</smiles>

A: $62 \% \pm 13 \%$ B: $97 \% \pm 1 \%$<smiles>O=C(Nc1ccc([18OH])cc1)c1ccccc1</smiles>

A: $34 \% \pm 6 \%$ B: $94 \% \pm 5 \%$

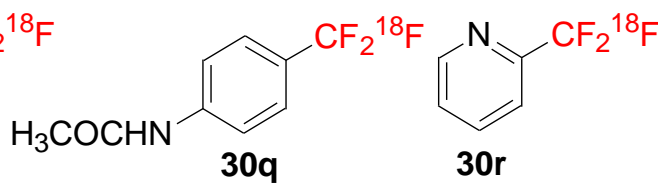

A: $40 \% \pm 1 \%$ B: $94 \% \pm 1 \%$

A: $89 \% \pm 4 \%$

Scheme 12. $\left[{ }^{18} \mathrm{~F}\right]$ trifluoromethylation of aryl iodides and aryl boronic acids.

\subsection{Difluoromethylation of alkynes}

In 2015 and 2016, an effective difluoromethylation of alkynes under a fluoroform atmosphere in the presence of $t$-BuOK or LHMDS as base was developed by the research groups of Shibata and Mikami (Scheme 13). ${ }^{49,50} \mathrm{~A}$ variety of arynes bearing either electron-donating or electron-withdrawing groups, such as methoxy (31a, 31e, 31g, 31k), phenyl 31c, dimethylamino 31b, bromo 31d, benzyloxy 31f and ester 31m were all tolerated, and afforded the desired products $\mathbf{3 2 a - g}, \mathbf{3 2 k}, \mathbf{3 1 m}$ in moderate yields. The heterocyclic alkynes $\mathbf{3 1} \mathbf{h}$ and $\mathbf{3 1} \mathbf{n}$ were also examed, and gave the products $\mathbf{3 2} \mathbf{h}, \mathbf{3 2 n}$ in $48 \%$ and $45 \%$ yields. In addition, the aliphatic alkynes $\mathbf{3 1 l}$ and 310 have also been well transformed to the difluoromethylated compounds (321: 38\%, 320: 72\%). 

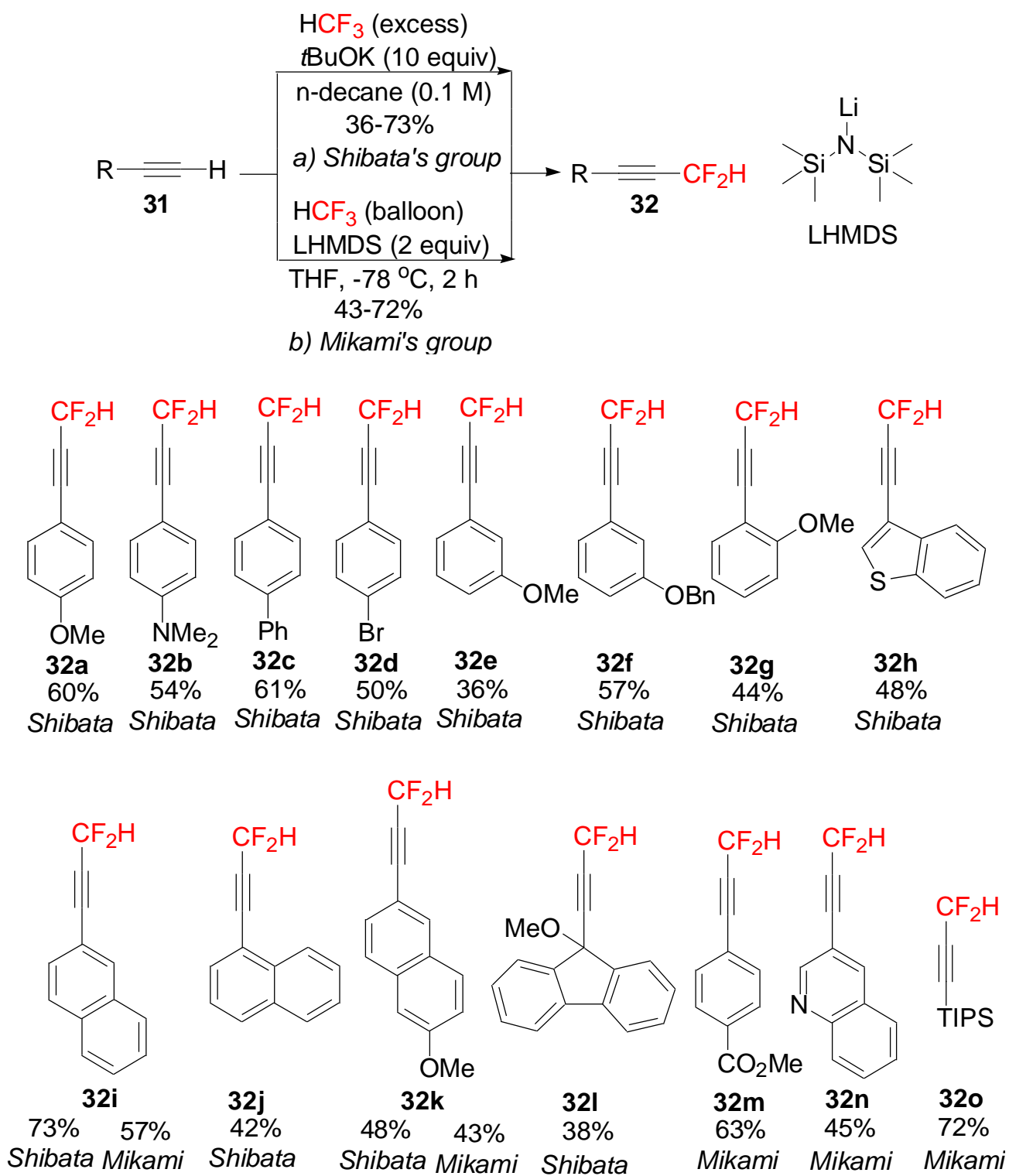

Scheme 13. Difluoromethylation of alkynes.

\subsection{Difluoromethylation of phenols, thiophenols and heterocyclic compounds}

In 2013 and 2014, the conversion of a series of substrates such as phenols, thiophenols, imidazoles, benzotriazoles and hydroxypyridines into their difluoromethylated derivatives 34, 36 and 38, with fluoroform as a difluorocarbene source in the presence of $\mathrm{KOH}$ as base, was demonstrated by the research group of Dolbier (Scheme 14). ${ }^{51,52}$ They showed that the phenols and thiophenols 33 containing either electron withdrawing or electron donating groups, performed well under the conditions of synthetic methods $A$ and $B$, and afforded the products $\mathbf{3 4}$ in moderate to excellent yields. ${ }^{51}$ Dolbier and co-workers found that, under the conditions of method B, difluoromethylation of heterocyclic compounds, such as imidazoles, benzimidazoles, indazoles and benzotriazoles (35) and hydroxypyridines (37), proved satisfactory, with moderate to good yields of the difluoromethylated products 36,38 being obtained. ${ }^{52}$ 


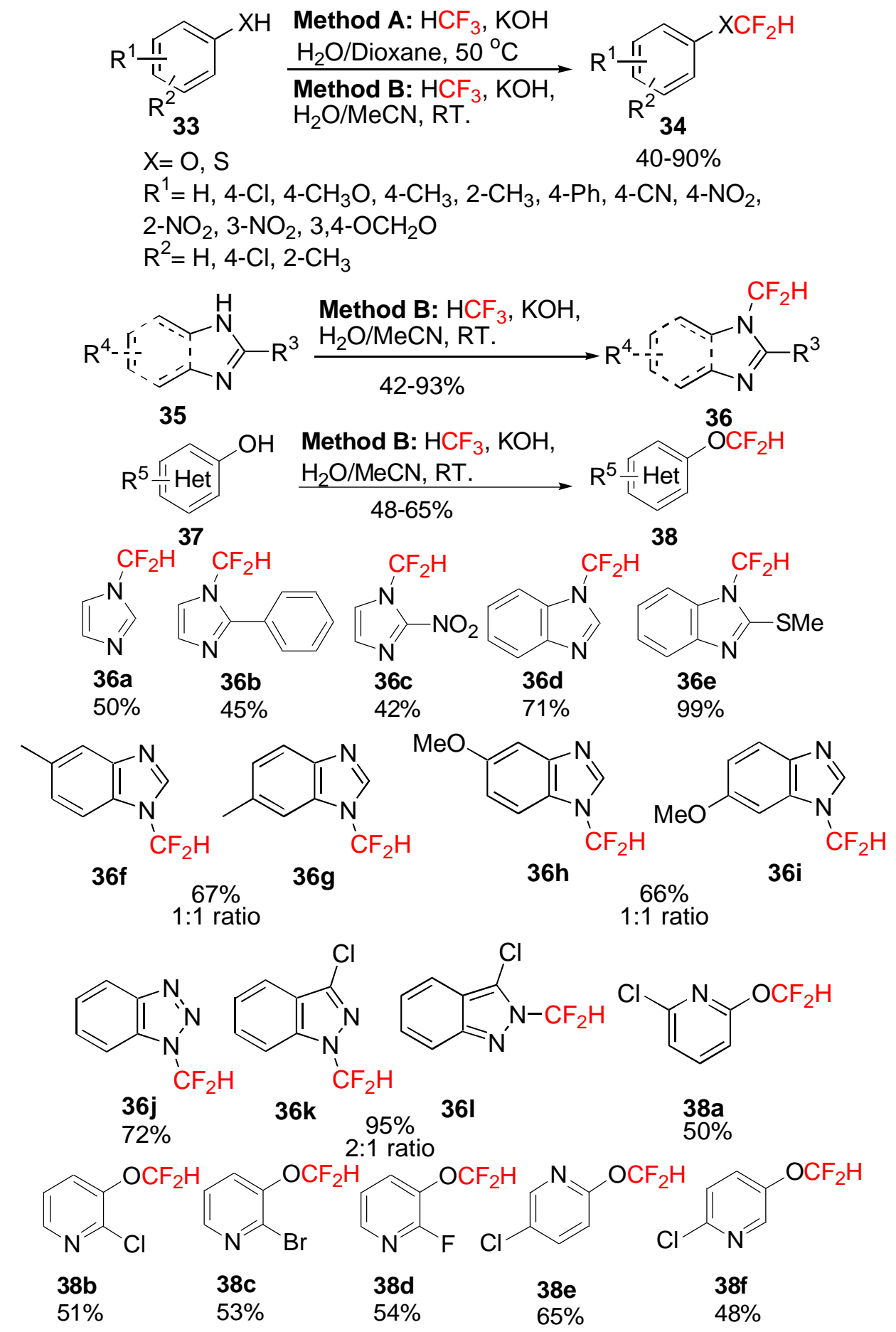

Scheme 14. Difluoromethylation of phenols, thiophenols and heterocyclic compounds.

\subsection{Difluoromethylation of nitriles}

In 2015, Mikami and co-workers reported a valuable difluoromethylation of nitrile compounds with fluoroform as a $\mathrm{CF}_{2} \mathrm{H}$ source in the presence of $n \mathrm{BuLi}$ as base (Scheme 15$) \cdot{ }^{53} \mathrm{It}$ was found that higher yields (40a-f: $\left.75-96 \%\right)$ were generally observed for the substrates 39a-f containing either an electron withdrawing or electron donating group in the position of the benzene ring. However, when the acyclic or cyclic $\alpha$-monoalkylated and 
vinylic substituted nitriles $\mathbf{3 9 h}-\mathbf{n}$ were employed for the difluoromethylation reactions, the difluoromethylated products 40h-n were obtained in moderate yields (39-53\%).
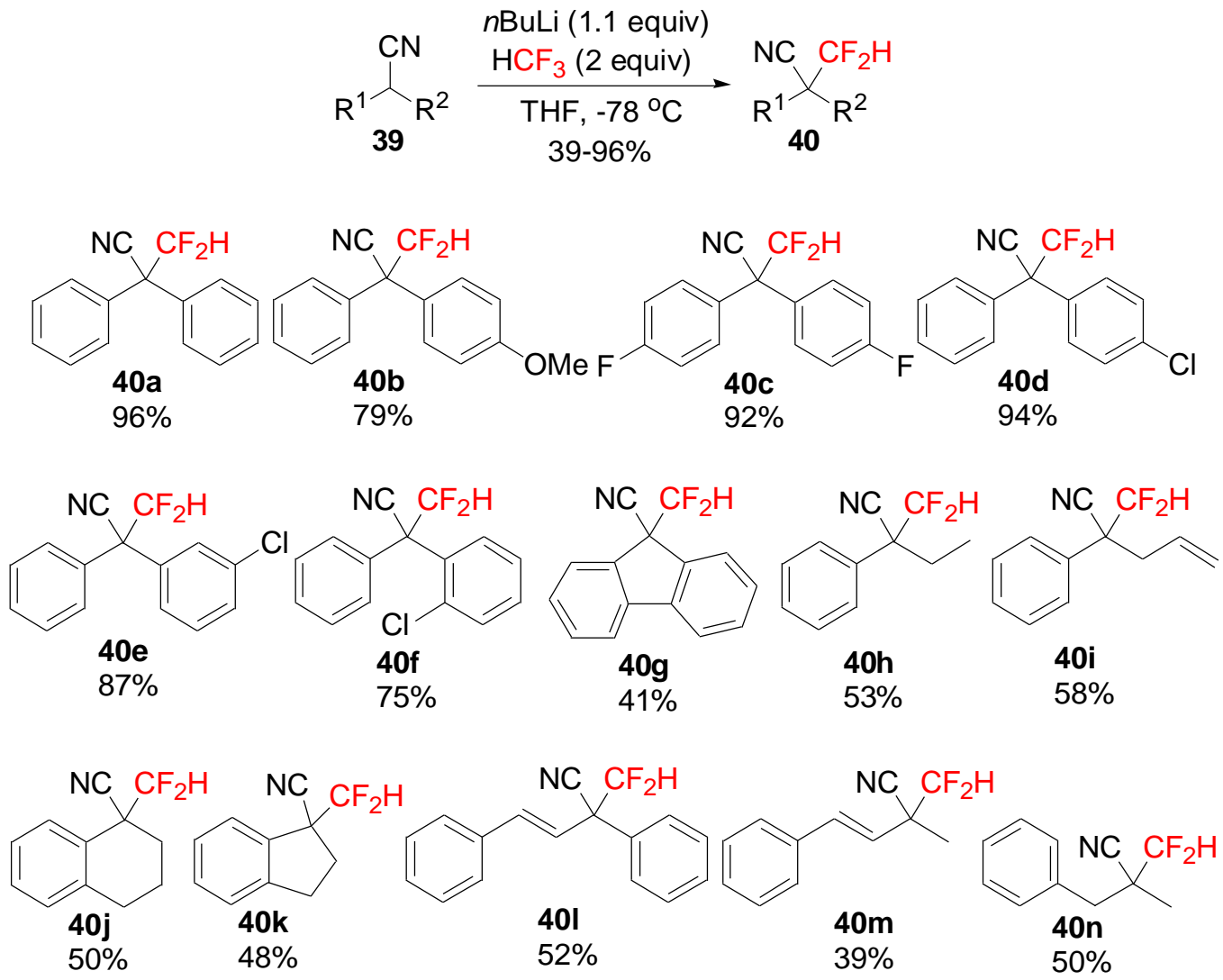

Scheme 15. Difluoromethylation of nitriles.

\section{Conclusions}

In summary, recent developments in trifluoromethylation and difluoromethylation by use of fluoroform are presented. In the presence of the strong bases, fluoroform can produce the trifluoromethyl anion, which is an unstable intermediate undergoing a decomposition reaction to generate difluorocarbene. Both the trifluoromethyl anion and difluorocarbene are very important intermediates in the trifluoromethylation or difluoromethylation reactions. In this review, we classified trifluoromethylation and difluoromethylation reactions under eight headings: (i) trifluoromethylation or difluoromethylation of carbonyl compounds, (ii) trifluoromethylation of sulfonyl fluorides, (iii) trifluoromethylation of epoxides, (iv) nucleophilic trifluoromethylation of silicon, boron, and sulfur-based compounds, (v) $\mathrm{CuCF}_{3}$ derived from fluoroform for the trifluoromethylation of aryl or heteroaryl halides, aryl boronic acids, arenediazonium salts and alkynes, (vi) difluoromethylation of alkynes, (vii) difluoromethylation of phenols, thiophenols and heterocyclic compounds, and (viii) difluoromethylation of nitriles. In most cases, the trifluoromethylated or difluoromethylated products were obtained in moderate to excellent yields. Compared with Umemoto's reagents, $\mathrm{NaSO}_{2} \mathrm{CF}_{3}$ and Togni's reagents, fluoroform is a non-toxic and harmless gas, and not easy to operate in the reactions. However, it can be converted to other stable $\mathrm{CF}_{3}$ reagents, such as $\mathrm{CuCF}_{3}$ and $\mathrm{CF}_{3} \mathrm{SiMe}_{3}$, which are relatively 
easy to operate in industrial production of the trifluoromethylated or difluoromethylated compounds. In spite of this, we also expect that the application of fluoroform in trifluoromethylation and difluoromethylation reactions will continue.

\section{Acknowledgements}

We would like to thank all authors whose names are listed in the references for their contributions to the organic fluorine chemistry described in this review. We also gratefully acknowledge the financial support by the research project (143144, AQJK15-08) from Chongqing Education Commission and Chongqing Vocational Institute of Safety Technology.

\section{References}

1. Wang, J.; Rosello, M.S.; Aceña, J. L.; Pozo, C.; Sorochinsky, A. E.; Fustero, S.; Soloshonok, V. A.; Liu, H. Chem. Rev. 2014, 114, 2432.

http://dx.doi.org/10.1021/cr4002879

2. Gillis, E. P.; Eastman, K. J.; Hill, M. D.; Donnelly, D. J. ; Meanwell, N. A. J. Med. Chem. 2015, $58,8315$. http://dx.doi.org/10.1021/acs.jmedchem.5b00258

3. Leroux, F.; Jeschke, P.; Schlosser, M. Chem. Rev. 2005, 105, 827. http://dx.doi.org/10.1021/cr040075b

4. Purser, S.; Moore, P. R.; Swallow, S.; Gouverneur, V. Chem. Soc. Rev. 2008, 37, 320. http://dx.doi.org/10.1039/B610213C

5. Zhang, C. Org. Biomol.Chem. 2014, 12, 6580. http://dx.doi.org/10.1039/C4OB00671B

6. Noto, N.; Miyazawa, K.; Koike, T.; Akita, M. Org. Lett. 2015, 17 , 3710. http://dx.doi.org/10.1021/acs.orglett.5b01694

7. Xu, J.; Luo, D. F.; Xiao, B.; Liu, Z. J.; Gong, T. J.; Fu, Y.; Liu, L. Chem. Commun. 2011, 47, 4300. http://dx.doi.org/10.1039/C1CC10359H

8. Besset, T.; Cahard, D.; Pannecoucke, X. J. Org. Chem. 2014, 79, 413. http://dx.doi.org/10.1021/jo402385g

9. Yasu, Y.; Koike, T.; Akita, M. Angew. Chem. Int. Ed. 2012, 51, 9567. http://dx.doi.org/10.1002/anie.201205071

10. Liu, H.; Gu, Z. H., Jiang, X. F. Adv. Synth. Catal. 2013, 355, 617. http://dx.doi.org/10.1002/adsc.201200764

11. Zhang, C. Adv. Synth. Catal. 2014, 356, 2895. http://dx.doi.org/10.1002/adsc.201400370

12. Mai, W. P.; Wang, J. T.; Yang, L. R.; Yuan, J. W.; Xiao, Y. M.; Mao, P.; Qu, L. B. Org. Lett. 2014, $16,204$. http://dx.doi.org/10.1021/ol403196h

13. Yu, X. L.; Chen, J. R.; Chen, D. Z.; Xiao, W. J. Chem. Commun. 2016, 52, 8275. http://dx.doi.org/10.1039/C6CC03335K 
14. Smyth, L. A.; Phillips, E. M.; Chan, V. S.; Napolitano, J. G.; Henry, R.; Shekhar, S. J. Org. Chem. 2016, 81, 1285.

http://dx.doi.org/10.1021/acs.joc.5b02523

15. Li, L.; Mu, X. Y.; Liu, W. B.; Wang, Y. C.; Mi, Z.; Li, C. J. J. Am. Chem. Soc. 2016, 138 , 5809. http://dx.doi.org/10.1021/jacs.6b02782

16. Liu, X.; Xu, C.; Wang, M.; Liu, Q. Chem. Rev. 2015, 115, 683. http://dx.doi.org/10.1021/cr400473a

17. Zhang, C. Arkivoc 2014, (i), 453. http://dx.doi.org/10.3998/ark.5550190.p008.656

18. Charpentier, J.; Fruh, N.; Togni, A. Chem. Rev. 2015, 115, 650. http://dx.doi.org/10.1021/cr500223h

19. Li, M.; Xue, X. S.; Guo, J.; Wang, Y.; Cheng, J. P. J. Org. Chem. 2016, 81, 3119. http://dx.doi.org/10.1021/acs.joc.5b02821

20. Matheis, C.; Jouvin, K.; Goossen, L. J. Org. Lett. 2014, 16, 5984. http://dx.doi.org/10.1021/ol5030037

21. Zhao, Y.; Huang, W.; Zheng, J.; Hu, J. Org. Lett. 2011, 13, 5342. http://dx.doi.org/10.1021/ol202208b

22. Tomashenko, O. A.; Grushin, V. V. Chem. Rev. 2011, 111, 4475. http://dx.doi.org/10.1021/cr1004293

23. Kyasa, S. Synlett 2015, 26, 1911. http://dx.doi.org/10.1055/s-0034-1380924

24. Kawai, H.; Yuan, Z.; Tokunaga, E.; Shibata, N. Org. Biomol.Chem. 2013, 11, 1446. http://dx.doi.org/10.1039/c3ob27368g

25. Shono, T.; Ishifune, M.; Okada, T.; Kashimura, S. J. Org. Chem. 1991, 56, 4. http://dx.doi.org/10.1021/jo00001a002

26. Russell, J.; Roques, N. Tetrahedron 1998, 54, 13771. http://dx.doi.org/10.1016/S0040-4020(98)00846-I

27. Symons, E. A.; Clermont, M. J. J. Am. Chem. Soc. 1981, 103, 3127. http://dx.doi.org/10.1021/ja00401a034

28. Langlois, B. R.; Billard, T. Synthesis 2003, 185. http://dx.doi.org/10.1055/s-2003-36812

29. Deng, X. Y.; Lin, J. H.; Xiao, J. C. Org. Lett. 2016, 18, 4384. http://dx.doi.org/10.1021/acs.orglett.6b02141

30. Zheng, Q.T.; Wei, Y.; Zheng, J.; Duan, Y.Y.; Zhao, G.; Wang, Z. B.; Lin, J. H.; Zheng, X.; Xiao, J. C. RSC Adv. 2016, 6, 82298. http://dx.doi.org/10.1039/C6RA20629H

31. Folléas, B.; Marek, I.; Normant, J. F.; Jalmes, L. S. Tetrahedron 1998, 39, 2973. http://dx.doi.org/10.1016/S0040-4039(98)00391-8

32. Barhdadi, R.; Troupel, M.; Périchon, J. Chem. Commun. 1998, 1251 http://dx.doi.org/10.1039/A801406J

33. Folléas, B.; Marek, I.; Normant , J. F.; Jalmes, L. S. Tetrahedron 2000, 56, 275. http://dx.doi.org/10.1016/S0040-4020(99)00951-5 
34. Large, S.; Roques, N.; Langlois, B. R. J. Org. Chem. 2000, 65, 8848.

http://dx.doi.org/10.1021/jo000150s

35. Prakash, G. K. S.; Jog, P. V.; Batamack, P. T. D.; Olah, G. A. Science 2012, 338, 1324.

http://dx.doi.org/10.1126/science.1227859

36. Zhang, Y.; Fujiu, M.; Serizawa, H.; Mikami, K. J. Fluorine Chem. 2013, 156, 367.

https://doi.org/10.1016/i.jfluchem.2013.07.018

37. Okusu, S.; Hirano, K.; Tokunaga, E.; Shibata, N. ChemistryOpen 2015, 4, 581.

http://dx.doi.org/10.1002/open.201500160

38. Born, D. V. D.; Herscheid, J. D. M.; Orru, R. V. A.; Vugts, D. J. Chem. Commun. 2013, 49, 4018. http://dx.doi.org/10.1039/c3cc37833k

39. lida, T.; Hashimoto, R.; Aikawa, K.; Ito, S.; Mikami, K. Angew. Chem. Int. Ed. 2012, 51, 9535. http://dx.doi.org/10.1002/anie.201203588

40. Zanardi, A.; Novikov, M. A.; Martin, E.; Buchholz, J. B.; Grushin, V. V. J. Am. Chem. Soc. 2011, $133,20901$. http://dx.doi.org/10.1021/ja2081026

41. Popov, I.; Lindeman, S.; Daugulis, O. J. Am. Chem. Soc. 2011, 133, 9286.

http://dx.doi.org/10.1021/ja2041942

42. Lishchynskyi, A.; Novikov, M. A.; Martin, E.; Escudero-Adán, E. C.; Novák, P.; Grushin, V. V. J. Org. Chem. 2013, 78, 11126.

http://dx.doi.org/10.1021/jo401423h

43. Mazloomi, Z.; Bansode, A.; Benavente, P.; Lishchynskyi, A.; Urakawa, A.; Grushin, V. V. Org. Process Res. Dev. 2014, 18, 1020.

http://dx.doi.org/10.1021/op500109v

44. Lishchynskyi, A.; Berthon, G.; Grushin, V. V. Chem. Commun. 2014, 50, 10237.

http://doi.org/10.1039/C4CC04930F

45. He, L.; Tsui, G. C. Org. Lett. 2016, 18, 2800.

http://dx.doi.org/10.1021/acs.orglett.6b00999

46. Ivashkin, P.; Lemonnier, G.; Cousin, J.; Grégoire, V.; Labar, D.; Jubault, P.; Pannecoucke, X. Chem. Eur. J. 2014, 20, 9514.

http://dx.doi.org/10.1002/chem.201403630

47. Zhang, C. P.; Cai, J.; Zhou, C. B.; Wang, X. P.; Zheng, X.; Gu, Y. C.; Xiao, J. C. Chem. Commun. 2011, $47,9516$. http://dx.doi.org/10.1039/C1CC13460D

48. Born, D. V. D.; Sewing, C.; Herscheid, J. D. M.; Windhorst, A. D.; Orru, R. V. A.; Vugts, D. J. Angew. Chem. Int. Ed. 2014, 53, 11046.

http://dx.doi.org/10.1002/anie.201406221

49. Okusu, S.; Tokunaga, E.; Shibata, N. Org. Lett. 2015, 17, 3802.

http://dx.doi.org/10.1021/acs.orglett.5b01778

50. Aikawa, K.; Maruyama, K.; Nitta, J.; Hashimoto, R.; Mikami, K. Org. Lett. 2016, 18, 3354.

http://dx.doi.org/10.1021/acs.orglett.6b01476

51. Thomoson, C. S.; Dolbier, W. R. J. Org. Chem. 2013, 78, 8904.

http://dx.doi.org/10.1021/jo401392f

52. Thomoson, C. S.; Wang, L.; Dolbier, W. R. J. Fluorine Chem. 2014, 168, 34. 
https://doi.org/10.1016/i.jfluchem.2014.08.015

53. Aikawa, K.; Maruyama, K., Honda, K.; Mikami, K. Org. Lett. 2015, 17, 4882.

http://dx.doi.org/10.1021/acs.orglett.5b02438

\section{Author's Biography}

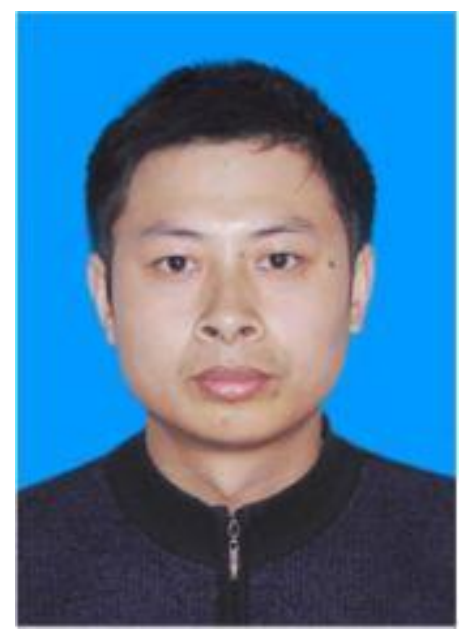

Cai Zhang was born in Anhui Province, P. R. of China. He received his BSc degree from Huaibei normal University (P. R. of China) in 2005, and obtained his MSc degree at Southwest University, Chongqing, P. R. of China, in 2009. From 2009 to 2013, he conducted Active Pharmaceutical Ingredient (API) research, such as cholesterol absorption inhibitors, antiplatelet drugs and antidiabetic drugs at pharmaceutical enterprises. In 2013 he moved to Chongqing Vocational Institute of Safety Technology, where he is engaged in the work of teaching and scientific research. His current research interests focus on the development of novel synthetic methodologies, such as hypervalent iodine reagents for application in organic synthesis, $\mathrm{C}-\mathrm{H}$ bond activation and fluorine chemistry. 